\title{
ACUTE MYOCARDIAL INFARCTION; FREQUENCY OF MODIFIABLE RISK FACTORS
}

1. FCPS Medicine

Assistant Professor Medicine,

Frontier Medical College

Abbottabad.

2. FCPS Surgery

Ayub Teaching Hospital,

Abbottabad

3. FCPS ENT

Associate Professor ENT,

Frontier Medical College

Abbottabad.

Correspondence Address: Dr. Rafaqat Malik

Assistant Professor Medicine,

Frontier Medical College Abbottabad.

rmalik706@gmail.com

Article received on:

22/12/2015

Accepted for publication:

22/01/2016

Received after proof reading:

10/03/2016

\section{Dr. Rafaqat Malik', Dr. Shazma Begum², Dr. Muhammad Nazar Afridi ${ }^{3}$}

\begin{abstract}
The frequency of modifiable risk factors of acute myocardial infarction varies greatly in different countries and populations of the world. Objective: To find out the frequency of modifiable risk factors in patients with acute myocardial infarction. Design: Cross-sectional study. Setting: Cardiology Department. Ayub Teaching Hospital Abbottabad, Period: 1st Jan 2015 and $30^{\text {th }}$ June 2015. Material and Methods: A total of 224 patients of acute myocardial infarction Patients were enquired about the presence of hypertension, diabetes mellitus, smoking and family history of ischemic heart disease. Fasting blood sugar and lipid profile were recorded. Results: Out of 224, 90.6\% patients had at least one risk factor. Hypertension was found to be the most common risk factor $(55.4 \%)$, followed by smoking $(43.8 \%)$ and Diabetes Mellitus (27.2\%). Dyslipidemia was found to be the least common (23.2\%) risk factor. Conclusion: Hypertension is the most common modifiable risk factor in patients of acute myocardial infarction, followed by smoking and diabetes.
\end{abstract}

Key words: Acute myocardial infarction, modifiable risk factors, Hypertension

Article Citation: Malik R, Begum S, Afridi MN. Acute myocardial infarction; frequency of modifiable risk factors. Professional Med J 2016;23(3):293-297. DOI:10.17957/ TPMJ/16.3223

\section{INTRODUCTION}

Acute myocardial infarction (AMI) is one of the most common diagnoses in hospitalized patients in industrialized countries. The early (thirty days) mortality rate from $\mathrm{AMI}$ is $30 \% .{ }^{1}$ About $37 \%$ of people who experience a coronary attack will die in the same year. ${ }^{2}$ The people of Indo-Asian origin have a high burden of coronary artery disease (CAD) which is now the leading cause of death in the Indo-Pakistan subcontinent. ${ }^{3}$

According to the INTERHEART study report, nine factors are responsible for $90 \%$ of myocardial infarctions. ${ }^{4}$ Modifiable risk factors include Diabetes mellitus, smoking, hypertension, hyperlipidemia, sedentary life style, obesity, stress and depression. ${ }^{5,6}$

Risk factors for ischemic heart disease and Acute Myocardial Infarction are on the rise in Pakistan. Eighteen percent of adult population suffers from hypertension. Smoking and tobacco use has increased and obesity is on the rise. ${ }^{7}$ Diabetes mellitus(DM) is found in $16.2 \%$ men and $11.7 \%$ women. ${ }^{8}$ Diabetes increases the risk of cardiovascular diseases (CVD) and mortality by about four times in women and about twofold in men. The combination of several risk factors further enhances the risk. ${ }^{4,5}$ Zia has reported that $30 \%$ of patients with an episode of myocardial infarction had type II diabetes mellitus. ${ }^{9}$ Treatment of hypertension and dyslipidaemia causes reduction in risk of myocardial infarction (MI). ${ }^{10}$ Increasing level of smoking increases the risk of AMI. Smoking is on the rise in many low and middle income countries, especially among young people and women. ${ }^{11}$

As there is variability in the prevalence of risk factors in different populations, a highly potent factor in one country could be less important in another one. Data is scanty on the level of knowledge about coronary artery disease (CAD) in Pakistani population. This study is an attempt to highlight the importance of modifiable risk factors of AMI in our population. 


\section{MATERIAL AND METHODS}

Our study was a cross-sectional survey of 224 patients with acute myocardial infarction who presented in the Cardiology Department of Ayub Teaching Hospital, Abbottabad from 1st Jan 2015 to $30^{\text {th }}$ June 2015. Diagnosis of AMI was based on international criteria. ${ }^{12}$ Patients were interviewed on a structured proforma. Verbal consent was taken from the patients who were willing to participate. In addition to collecting basic demographic details, patients were asked about their hypertension and diabetes mellitus status. Information was also obtained regarding smoking and history of ischemic heart disease in first degree relatives. Patients with AMI having age above 18 years were included in the study. Patients having recurrent MI and family history of ischemic heart disease were excluded from the study. Diagnosis of DM was based on past diagnosis by a physician, intake of anti-diabetic medications or post-admission fasting blood sugar values using the 1999 diagnostic criteria recommended by the World Health Organization (WHO)..$^{13}$ Hypertension was attributed if blood pressure exceeded $\geq 140 / 90$ $\mathrm{mmHg}$, or if a patient was on anti-hypertensive medication. Subjects were considered to have dyslipidemia if either cholesterol or triglycerides was increased (cholesterol $\geq 5.2 \mathrm{mmol} / \mathrm{L}$, triglycerides $\geq 1.69 \mathrm{mmol} / \mathrm{L}){ }^{14}$ Smoking was defined as smoking of at least 100 cigarettes during lifetime. The data was managed using Statistical package for social sciences (SPSS, v17). P-value was calculated by student t-test for the risk factors and it was found to be significant if p-value was $\leq 0.05$.

\section{RESULTS}

Our study included 224 cases of acute myocardial infarction. Gender and age distribution was as shown in Table-I.

\begin{tabular}{|c|c|c|c|c|c|}
\hline Gender & No. of patients & Minimum & Maximum & Mean & Std. Deviation \\
\hline Female & $69(30.8 \%)$ & 31 & 95 & 61.14 & 13.018 \\
\hline Male & $155(69.2 \%)$ & 26 & 90 & 57.66 & 13.054 \\
\hline Total & $224(100 \%)$ & 26 & 95 & 58.74 & 13.113 \\
\hline
\end{tabular}

Table-I. Age distribution

Distribution of different risk factors is shown in Table-II. Hypertension was found to be the most common risk factor (55.4\%).

\begin{tabular}{|c|c|c|}
\hline Risk factor & No. of patients & Percentage (\%) \\
\hline Hypertension & 124 & 55.4 \\
\hline Smoking & 98 & 43.8 \\
\hline Diabetes Mellitus & 61 & 27.2 \\
\hline Dyslipidemia & 52 & 23.2 \\
\hline
\end{tabular}

Table-II. Frequency of risk factors

Hypertension was significantly more frequent in females $(p=0.016)$ while smoking was more in males $(p=0.00)$. Diabetes mellitus was significantly more common in females $(p=0.001)$. Gender difference was statistically insignificant $(p=0.57)$ for dyslipidemia, as is shown in Table-III.

\begin{tabular}{|c|c|c|c|c|}
\hline P-value & No & Yes & Gender & Risk factor \\
\hline \multirow{2}{*}{0.016} & $77(49.7 \%)$ & $78(50 \%)$ & Male & Hypertension \\
\hline \multirow{2}{*}{0.000} & $25(33.3 \%)$ & $44(66.7 \%)$ & Female & Smoking \\
\hline \multirow{2}{*}{0.001} & $61(39.4 \%)$ & $94(66.6 \%)$ & Male & Female \\
\hline \multirow{2}{*}{0.57} & $65(94.2 \%)$ & $4(5.8 \%)$ & Male & Diabetes Mellitus \\
\hline & $123(79.4 \%)$ & $32(20.6 \%)$ & Female & \\
& $40(58 \%)$ & $29(42 \%)$ & Male & Dyslipidemia \\
\hline
\end{tabular}

Table-III. Gender distribution of risk factors 


\section{DISCUSSION}

Ischemic heart disease is responsible for about $40 \%$ deaths in Western countries. Acute myocardial infarction is one of the major health problems throughout the world.$^{15}$ cardiovascular diseases like myocardial infarction and stroke have become the leading causes of mortality and morbidity in Pakistan. Comprehensive data of the profile and characteristics of AMI patients in Pakistan is not only inadequate but also major surveys have not been published. ${ }^{16}$

Acute Myocardial Infarction Risk Factor Assessment in Brazil (AFIRMAR) reported that smoking, diabetes mellitus, waist to hip ratio, hypertension, hyperlipidemia and family history of CAD were the main risk factors for AMI. ${ }^{7}$

Acute myocardial infarction is more common in males who are affected at a relatively younger age compared to females. Coronary artery disease affects South Asians at a relatively younger age as compared to western population. ${ }^{17,18}$ Our study included 224 cases of acute myocardial infarction. Of these, $69.2 \%$ were males and $30.8 \%$ were females. Our results match those of Abbas et al and Ahmed who showed that $73.8 \%$ of AMI patients were male. ${ }^{19}$ Shafique et al also found that majority ( $87 \%$ ) of AMI of patients were male. ${ }^{20}$ Male patients were also a dominant entity (85\%) in another study conducted in USA and Canada. ${ }^{21}$ Similarly data of Singapore Myocardial Infarction Registry, between 1988 and 1997 showed that men were four times more prone to have acute Ml than women. ${ }^{22}$

In a study, comparing ACS in South Asians with Caucasians, it was found that Asians are affected at about 10 years younger age.$^{23}$ In our study, mean age was $58.74 \pm 13.113$ years. Our patients mean age was slightly higher than other studies conducted in the region but lower than western population. Jafary et al found mean age of patients with AMI to be $52.5 \pm 10.8$ years. ${ }^{16}$

Wilson and Agostino et al showed that hypertension is an important risk factor associated with AMI. ${ }^{24}$ In our study hypertension was found to be the most common risk factor associated with AMl being present in $55.4 \%$ of patients. Hypertension was significantly $(p=0.016)$ more common in females $(66.7 \%)$ than male patients (50.3\%). Hypertension also figured prominently in a study by Jafary et al who showed that more than half $(55.2 \%)$ of the AMI patients had hypertension. ${ }^{16}$

Smoking appeared to be the second most common risk of AMl in our study and was noted in $52 \%$ patients. Jafary et al also showed similar results. ${ }^{16}$ In our study, smoking was significantly $(p=0.00)$ more common in male patients $(66.6 \%)$ than females (5.8\%). A study, conducted in Punjab institute of cardiology, showed that smoking was the most prevalent (63.4\%) risk factor in young coronary artery disease patients. ${ }^{25}$ Begom et al showed that smoking was $44.6 \%$ prevalent in male patient with coronary artery disease. ${ }^{26}$

Diabetes increases risk of coronary heart disease (CHD) by two to four times. ${ }^{27}$ In a hospital based case control study, conducted in a rural population of India, cases of AMI were twice as likely to have history of diabetes compared to controls. ${ }^{28}$ In our study diabetes mellitus was noted in $27.2 \%$ of patients It was important to note that diabetes was significantly more prevalent $(p=0.001)$ in female patients $(42 \%)$ than males $(20.6 \%)$.

Ridker et al demonstrated that total cholesterol was significantly high in patients with AMI than controls. ${ }^{29}$ In our study $23.2 \%$ patients had hyperlipidemia. Our results were similar to those of Ahmed and Shafique. ${ }^{20}$ They noted that $19 \%$ of AMI patients had hyperlipidemia. Jafary et al showed that $18.2 \%$ of AMI cases had hyperlipidemia. ${ }^{16}$ A study, carried out in rural population of India, found that hyperlipidemia was not significantly associated with AMI. ${ }^{27} \mathrm{~A}$ study conducted in Latin America found that significantly higher risk of AMI was associated with hyperlipidemia. ${ }^{11}$

\section{CONCLUSION}

From our study, it is concluded that hypertension is the most common while dyslipidemia is the least common risk factor of AMI. Hypertension 
and diabetes mellitus are significantly more common in females while smoking is significantly more common in males. Dyslipidemia is equally prevalent in both genders.

Copyright(C) 22 Jan, 2016.

\section{REFERENCES}

1. Antman EM, Localzo J. ST-segment elevation myocardial infarction. In: Kasper DL, Hauser SL, Jameson JL, Fauci AS, Longo DL, Localzo J. Harrison's Principles of Internal Medicine.19th ed. New York: The McGraw-Hill companies 2015; 1599-1611.

2. Bashore TM, Granger CB, Jackson K, Patel MR. Heart Disease. In: Papadakis MA, McPhee SJ. Current Medical Diagnosis and Treatment.54th ed. New York: McGraw -Hill companies 2015; 320-431.

3. The future of CVD. In: Mackay J, Mensah G. The Atlas of Heart Disease and Stroke Geneva, Switzerland: World Health Organization 2004:74-5.

4. 1999 Update: ACC/AHA Guidelines for the Management of patients with Acute Myocardial Infarction: A report of the American College of Cardiology / American Heart Association Task Force on Practice Guidelines (Committee on Management of Acute Myocardial Infarction). J Am Cardiol 1999; 34:890-911. Available at http://content.onlinejacc.org/ article.aspx?articleid $=1125993$.

5. Jafar $\mathrm{TH}$, Jafary $\mathrm{FH}$, Jessani $\mathrm{S}$, Chaturvedi N. Heart disease epidemic in Pakistan: Women and men at equal risk. Am Heart J 2005; 150: 221-6.

6. Iqbal MJ, Azhar M, Javed MT, Tahira I. Study on STsegment Elevation Acute Myocardial Infarction (STEMI) in Diabetic and non-diabetic patients. Pak J Med Sci 2008; 24(6):786-91.

7. Piegas LS, Avezum A, Pereira JCR, Neto JM, Hoepfner C, Farran JA, et al. for the AFIRMAR Study Investigators. Risk factors for myocardial infarction in Brazil.Am Heart J 2003; 146:331-8.

8. Ismail J, Jafar $\mathrm{TH}$, Jafary $\mathrm{FH}$, White $\mathrm{F}$, Faruqi AM, Chaturvedi N. Risk factors for non-fatal myocardial infarction in South Asian adults. Heart 2004; 90:25963.

9. Zia S, Hassan ZU, Sahibzada WA. A comparison between patients with acute myocardial infarction alone or with other cardiovascular diseases and patients of acute myocardial infarction with type 2 diabetes. J Post grad Med Inst 2004; 18:153-61

10. Antman EM, Localzo J. Ischemic heart disease. In: Kasper DL, Hauser SL, Jameson JL, Fauci
AS, Longo DL, Localzo J. Harrison's Principles of Internal Medicine.19th ed. New York: The McGraw-Hill companies 2015; 1578-92.

11. Lanas F, Avezum A, Bautista LE, Diaz R, Luna M, Islam S. Risk Factors for Acute Myocardial Infarction. The INTERHEART, Latin American Study. Circulation 2007; 115:1067-74.

12. Alpert JS, Thygesen K, Antman E, Basand JP. Myocardial infarction redefined - a consensus document of The Joint European Society of Cardiology/American College of Cardiology Committee for the redefinition of myocardial infarction. J Am Coll Cardiol 2000; 36(3):959-969.

13. World Health Organization. Definition, diagnosis and classification of diabetes mellitus and its complications. Part 1: diagnosis and classification of diabetes mellitus. Report of a WHO consultation. Geneva: World Health Organization, 1999. Available at : http://www.who.int/iris/handle/10665/66040.

14. National Cholesterol Education Program. Third Report of the National Cholesterol Education Program (NCEP) Expert Panel on Detection, Evaluation, and Treatment of High Blood Cholesterol in Adults (Adult Treatment Panel III) final report. Circulation 2002; 106:3143-421. Available at : http://www.ncbi.nlm.nih. gov/pmc/articles/PMC1484657/.

15. Deewood MA, Spres J, Mtske R. Prevalence of total coronary occlusion during the early hours of transmural myocardial infarction. $N$ Eng $J$ Med 1980; 303:897-901.

16. Jafary $M H$, Samad $A$, Ishfaq $M$, Jawaid SA, Ahmed M, Vohra EA. Profile of Acute Myocardial Infarction in Pakistan. Pak J Med Sci 2007; 23 (4):485-9.

17. Enas EA, Yusuf S, Jawahar M. Meeting of international working group on coronary artery disease in South Asians. Indian Heart J 1998; 48:727-32.

18. Enas EA, Graig A, Davidson M. Coronary artery disease and its risk factors in the first generation Asians to USA. Indian Heart J 1996; 48:343-54.

19. Abbas S, Riaz A, Malik N. Risk factors for coronary artery disease. Pak Armed Forces Med J 2003; 53(1):12-9

20. Ahmed I, Shafique Q, Myocardial Infarction under 40: Risk factors and coronary angiographic findings. An King Edward Med Coll 2003; 9 (4):262-5.

21. Boden WE, O'rouke RA, CORAGE trial group, The evolving pattern of coronary artery disease in the US and Canada: Baseline characteristics of the 
Clinical Outcomes Utilizing Revascularization and Aggressive Drug Evaluation (COURAGE) trial. Am J Cardiol 2007; 99 (2):208-12.

22. Kam R, Cutter J, Chew SK. Gender differences in outcome after an acute myocardial infarction. Singapore Med J 2002; 43:243-8.

23. Teoh M, Lalondrelle S, Grocott-Mason R, Dubrey SW. ACS and its presentation in Asian Caucasian patients in Britain. Heart 2007; 93:183-8.

24. Wilson PW, Agostino RB. Prediction of CHD using risk factor categories. Circulation 1998; 97:1837-47.

25. Noeman A, Ahmed N, Azhar M. Coronary artery disease in young: Faulty life style or Here do familial or both. Annals 2007; 13 (2):162-4.
26. Begom R, Singh RB, Prevalence of coronary artery disease and its risk factors in the urban population of South and North India. Acta Cardiol 1995; 50: 22740.

27. Gu K, Cowie CC, Haris Ml, Mortality in adults with and without diabetes in a national cohort of US population. Diabetes care 1998; 21: 1138-45.

28. Patil SS, Joshi R, Gupta G, Reddy MVR, Pai M, Kalantri SP. Risk factors for acute myocardial infarction in a rural population of central India: a hospital based case control study. Natl Med J India 2004; 17:189-94.

29. Ridker PM, Buring JE, Matias M, Hennekens $\mathrm{CH}$. Prospective study of $\mathrm{C}$-reactive protein and the risk of future cardiovascular events among apparently healthy women. Circulation 1998; 98: 731-3.

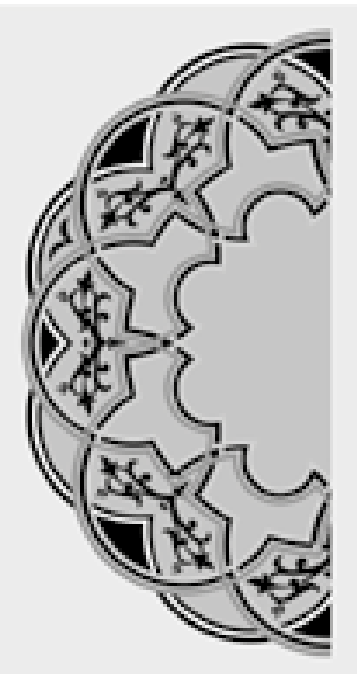

\section{"See the bad inside yourself, and see the good inside others."}

Imam Ali (AS)

AUTHORSHIP AND CONTRIBUTION DECLARATION

\begin{tabular}{|c|l|l|l|}
\hline Sr. \# & \multicolumn{1}{|c|}{ Author-s Full Name } & \multicolumn{1}{|c|}{ Contribution to the paper } & Author=s Signature \\
\hline 1 & Dr. Rafaqat Malik & Author \\
\hline 2 & Dr. Shazma Begum & Co-author \\
3 & Dr. Muhammad Nazar Afridi & Co-author \\
\hline
\end{tabular}

